J. Dairy Sci. 100:253-264

https://doi.org/10.3168/jds.2016-11609

(c) 2017, THE AUTHORS. Published by FASS and Elsevier Inc. on behalf of the American Dairy Science Association ${ }^{\circledR}$.

This is an open access article under the CC BY-NC-ND license (http://creativecommons.org/licenses/by-nc-nd/3.0/).

\title{
Prediction and validation of residual feed intake and dry matter intake in Danish lactating dairy cows using mid-infrared spectroscopy of milk
}

\author{
N. Shetty, ${ }^{1}$ P. Løvendahl, M. S. Lund, and A. J. Buitenhuis \\ Department of Molecular Biology and Genetics, Center for Quantitative Genetics and Genomics, Aarhus University, DK 8830 Tjele, Denmark
}

\begin{abstract}
The present study explored the effectiveness of Fourier transform mid-infrared (FT-IR) spectral profiles as a predictor for dry matter intake (DMI) and residual feed intake (RFI). The partial least squares regression method was used to develop the prediction models. The models were validated using different external test sets, one randomly leaving out $20 \%$ of the records (validation A), the second randomly leaving out $20 \%$ of cows (validation B), and a third (for DMI prediction models) randomly leaving out one cow (validation $\mathrm{C}$ ). The data included 1,044 records from 140 cows; 97 were Danish Holstein and 43 Danish Jersey. Results showed better accuracies for validation A compared with other validation methods. Milk yield (MY) contributed largely to DMI prediction; MY explained 59\% of the variation and the validated model error root mean square error of prediction (RMSEP) was $2.24 \mathrm{~kg}$. The model was improved by adding live weight (LW) as an additional predictor trait, where the accuracy $\mathrm{R}^{2}$ increased from 0.59 to 0.72 and error RMSEP decreased from 2.24 to $1.83 \mathrm{~kg}$. When only the milk FT-IR spectral profile was used in DMI prediction, a lower prediction ability was obtained, with $\mathrm{R}^{2}=0.30$ and $\mathrm{RMSEP}=2.91$ $\mathrm{kg}$. However, once the spectral information was added, along with MY and LW as predictors, model accuracy improved and $\mathrm{R}^{2}$ increased to 0.81 and RMSEP decreased to $1.49 \mathrm{~kg}$. Prediction accuracies of RFI changed throughout lactation. The RFI prediction model for the early-lactation stage was better compared with across lactation or mid- and late-lactation stages, with $\mathrm{R}^{2}=$ 0.46 and $\mathrm{RMSEP}=1.70$. The most important spectral wavenumbers that contributed to DMI and RFI prediction models included fat, protein, and lactose peaks. Comparable prediction results were obtained when using infrared-predicted fat, protein, and lactose instead of full spectra, indicating that FT-IR spectral data do not add significant new information to improve DMI
\end{abstract}

Received June 14, 2016.

Accepted September 30, 2016.

${ }^{1}$ Corresponding author: nisha.shetty@mbg.au.dk and RFI prediction models. Therefore, in practice, if full FT-IR spectral data are not stored, it is possible to achieve similar DMI or RFI prediction results based on standard milk control data. For DMI, the milk fat region was responsible for the major variation in milk spectra; for RFI, the major variation in milk spectra was within the milk protein region.

Key words: dry matter intake, residual feed intake, spectroscopy, prediction, validation

\section{INTRODUCTION}

Dry matter intake is a primary factor affecting animal performance. In cattle forage, DMI is integral in energy intake and production performance (Waldo and Jorgensen, 1981; Dado and Allen, 1994). Feed costs are the largest expense for dairy producers due to the energy required for lactation (Vallimont et al., 2011). Producers and nutritionists closely assess feeding programs to identify new opportunities to improve efficiency. Feed or DMI efficiencies have been applied to monitor dairy cattle performance. In dairy cows, feed efficiency is used as a measure to determine the capacity of lactating cows to convert feed nutrients into ECM or milk components. In simplest terms, feed efficiency equals kilograms of milk produced per kilogram of dry matter consumed (Hutjens, 2005). Feed efficiency measurements become increasingly important during periods of decreased profit margins; that is, high input and low return. Feed-efficient cows consume less energy and emit less methane (Connor et al., 2012). Thus, improving feed efficiency for dairy cows results in economic and environmental benefits (Basarab et al., 2013). Dairy cow efficiency can be defined in several ways. Among these, a commonly used method is residual feed intake (RFI). Residual feed intake is an alternative to the ratio-based (i.e., input:output) measure, because feed efficiency in lactating cows must consider the contribution of mobilization of body reserves to the cow's energy supply (Berry and Crowley, 2013). Residual feed intake is defined as the difference (in energy units) between feed intake energy and the sum of energy found in feed products and energy used in maintenance. 
The concept of selecting for improved feed efficiency or RFI is highly attractive, but practical implementation might be challenging, primarily because individual feed intake records are unavailable in commercial dairy herds. Dry matter intake is the key component to calculate feed efficiency. Genetic assessment of dairy cows requires reasonably large data sets. However, only small data sets are generally available for feed intake because of the difficulty and expense involved in measuring DMI. A promising option could be use of Fourier transform mid-infrared (FT-IR) spectroscopy on milk samples to predict DMI or RFI traits; FT-IR spectroscopy is a rapid and cost-effective tool for recording phenotypes at the population level and is already widespread for standard milk sample analysis.

Fourier transform mid-infrared spectroscopy studies the interactions between light and matter and is method of choice worldwide to quantify milk components, including fat, protein, and lactose during routine milk analyses. Recently, FT-IR spectroscopy was used to predict more detailed milk quality traits, such as individual milk fatty acids and proteins (Rutten et al., 2009, 2011; Bonfatti et al., 2011; Soyeurt et al., 2011; De Marchi et al., 2014). McParland et al. (2011, 2012, 2014) reported that energy status (intake and balance) and RFI can be predicted phenotypically using FTIR. The additional benefit of using milk FT-IR is that spectral data are routinely generated for all individual milk samples, and DMI or RFI can be predicted on all milk-recorded animals at no additional cost.

In the present study, we elucidated the efficacy of FT-IR spectroscopy to predict DMI and RFI and evaluated the additional value of using FT-IR milk spectral profiles to improve DMI and RFI prediction models, along with other available informative traits. The objectives of this study were as follows: (1) to evaluate the potential of FT-IR to predict DMI and RFI using partial least squares regression (PLSR); (2) to identify and asses the most important FT-IR regions or wavenumbers in the prediction of DMI and RFI; and (3) to validate the developed prediction models for robustness.

\section{MATERIALS AND METHODS}

\section{Data Collection}

Data were collected from the Danish Cattle Research Centre (DKC, Foulum). Milk samples were collected 2 to 6 times per week (April to August 2015) and sent to the Eurofins-Steins laboratory (Vejen, Denmark) for FT-IR spectral analyses using MilkoScan FT+ (Foss, Hillerød, Denmark). Concurrently, milk yield (MY), fat, protein and lactose contents, DMI, live weight $(\mathbf{L W})$, and BCS were recorded. The data analyzed included 1,044 DMI $(\mathrm{kg} / \mathrm{d})$ averaged per lactation week from 140 cows $(97$ Holstein and 43 Jersey). Corresponding weekly averages for daily MY (kg/d), LW (kg), and FT-IR-predicted fat, protein, and lactose contents were available for all these records. Body condition was scored to the nearest half unit on the Danish scale (Kristensen, 1986; derived from Lowman et al., 1976) from 1 to 5 on d 2, 14, 28, $42,56,84,112,168$, and 224 after calving (Løvendahl et al., 2010). Body condition scoring was breed-specific and was scored every other week; BCS records were available as 596 records from 137 cows, because BCS records were missing for 3 cows. The 4,089 FT-IR spectral data records representing daily milk samples from the 140 cows were similarly averaged on a weekly basis, corresponding to the 1,044 DMI weekly average records. Dehareng et al. (2012) reported this approach, where each cow was milked twice daily and FT-IR spectral data were averaged to represent a daily milk spectrum, which was subsequently associated with recorded daily $\mathrm{CH}_{4}$ data.

\section{RFI Computation}

We describe the feed efficiency measure, RFI, as the residual from a linear regression model, where DMI is regressed on ECM and metabolic body weight (MBW):

$$
\mathrm{RFI}=\mathrm{DMI}-\beta 1 \times \mathrm{ECM}-\beta 2 \times \mathrm{MBW},
$$

where ECM was calculated using the following formula proposed by Sjaunja et al. (1991):

$$
\begin{gathered}
\mathrm{ECM}=(\text { yield } / 3,140) \times[(383 \times \text { fat }) \\
+(242 \times \text { protein })+(157 \times \text { lactose })+20.7] .
\end{gathered}
$$

Yield was in kilograms; fat, protein, and lactose contents are in percent; and MBW represents weekly metabolic BW (i.e., $\mathrm{LW}^{0.75}$ ).

\section{Prediction Model Development}

Prediction models were developed using the PLSR method (Wold et al., 1983; Martens and Naes, 1989). The method has been widely used in quantitative spectroscopy to determine a relationship between spectroscopic (predictors) and related chemical or physical data; that is, predictor(s). In the PLSR method, predictors are reduced to a smaller set of uncorrelated orthogonal components called latent variables, and a least squares regression is performed on the latent 
variables instead of on the original data. Partial least squares regression performs well when the number of predictors is greater than the number of observations, and when strong collinearity exists between them; for example, in spectroscopic data.

The FT-IR spectral data were composed of 1,060 infrared frequencies (wavenumbers), which represented infrared light absorption through the milk sample at wavenumber regions ranging from 925 to $5,008 \mathrm{~cm}^{-1}$. Due to high water absorption, $\mathrm{O}-\mathrm{H}$ stretching (between $\sim 1,600 \mathrm{~cm}^{-1}$ and $1,700 \mathrm{~cm}^{-1}$ ) and $\mathrm{O}-\mathrm{H}$ bending $\left(>3,005 \mathrm{~cm}^{-1}\right)$ regions were omitted and the remaining 511 spectral data points were maintained for further analyses.

Rinnan et al. (2009) showed that spectral data preprocessing was integral for robust analyses, whether analyses involved exploratory, classification or prediction studies. Spectral data pre-processing can be defined as mathematical data manipulation to enhance spectral features or remove or reduce unwanted sources of variation before the development of the calibration model. We applied Savitzky-Golay (Savitzky and Golay, 1964) first derivatives with filter width 7, polynomial order 2, and mean centering for weekly averaged FT-IR data. Different types of variables with different units were measured; for example, FT-IR data, MY, $\mathrm{LW}$, and BCS; therefore, predictor traits were equally scaled using auto-scaling.

Over- or under-fitting in the final PLSR model was avoided by determining the optimal component number based on the lowest root mean square error of cross-validation (RMSECV) value using 10 random iterations. Outlier analysis was performed using PLSR Hotelling $\mathrm{T}^{2}$ versus Q-residual plots and leverage versus studentized residual plots. Predictive capacity of the calibration models was evaluated using coefficients of determination for calibration $\left(\mathbf{R}^{2}{ }_{\text {Cal }}\right)$ and for validation $\left(\mathbf{R}^{2}{ }_{\text {Val }}\right)$ along with root mean square error of calibration (RMSEC) and prediction (RMSEP) in the validation data set (Esbensen, 2000).

The robustness of generated prediction model was evaluated by dividing the data into calibration and validation data sets. Three different calibration and validation data sets with 50 random iterations were used to confirm and compare the models for robustness:

- Validation A: $20 \%$ ( $\mathrm{n}=140$ cows) of the records were randomly left out for validation and the remaining $80 \%$ ( $\mathrm{n}=140$ cows) of the data were used to train the model.

- Validation B: Of the 140 cows, $20 \%$ ( $\mathrm{n}=28$ cows) were randomly left out for validation and the re- maining $80 \%$ ( $\mathrm{n}=112$ cows) of the data were used to train the model.

- Validation C: One cow was randomly left out from the data for validation and the remaining $(\mathrm{n}=$ 139 cows) were used to train the model.

Prediction models for DMI and RFI were developed across and within the following lactation stages: early: 1 to $9 \mathrm{wk}$ (100 records from 31 cows); mid: 10 to $22 \mathrm{wk}$ (298 records from 61 cows); and late: 23 to $44 \mathrm{wk}$ (646 records from 105 cows).

\section{Variable Selection}

In this study, we used recursive weighted partial least squares (rPLS), a recently proposed variable selection method (Rinnan et al., 2014). In rPLS, the response variable $y$ is used to direct variable reweighting in an iterative (i.e., recursive) fashion. The regression coefficients are used as weights on the original data matrix. The rPLS procedure is based on repeated PLS models and the current regression coefficients are applied as cumulative weights on the independent variables $x$. Regression weights close to zero indicate unimportant variables and large absolute weights indicate important variables (Rinnan et al., 2014).

We used MATLAB (version R2015a, The Mathworks, Natwick, MA) along with PLS toolbox (Eigenvector Research Inc., Manson, WA) was used to perform all analysis in this study.

\section{RESULTS}

\section{Data Description}

Descriptive statistics of the traits measured for DMI and RFI prediction model development are shown in Table 1. Holstein cows exhibited higher LW than Jerseys. Holstein average LW was $683.78 \mathrm{~kg}$ and Jerseys averaged $525.13 \mathrm{~kg}$. Holsteins had greater DMI than Jerseys. Fat and protein contents were lower in Holsteins compared with Jersey cows. Milk fat in Holstein cows ranged from 2.39 to $6.57 \%$, with an average of $3.84 \%$; milk protein ranged from 2.61 to $4.53 \%$ and averaged $3.49 \%$. Milk fat in Jersey cows was between 4.29 and $8.53 \%$, with an average $5.86 \%$; and milk protein was from 3.43 to $5.06 \%$ with an average of $4.31 \%$. Average BCS scores for Holsteins and Jersey cows were not comparable due to breed-specific BCS standards; however, both breeds had the same standard deviation of 0.17 . Jersey cows were more feed efficient than Holsteins. 


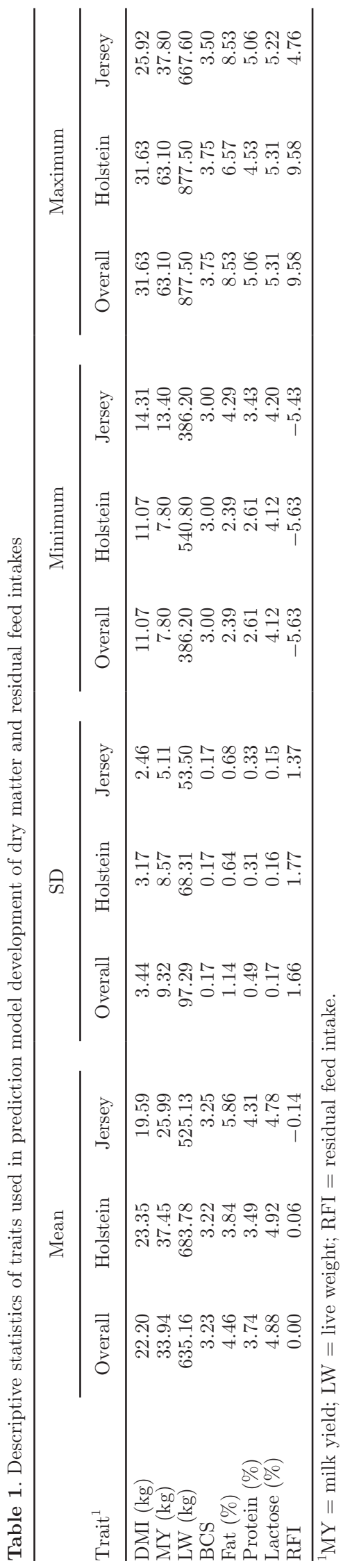

\section{DMI Prediction and Validation}

Forty-six total records with notably high leverage values, residual values, or both, compared with the rest of the records were eliminated as outliers. These records were not from particular cows and were deviating for FT-IR spectral profile. When these outlying records were checked for other traits, most of the records also had relatively high fat content values. The DMI prediction model results using different trait combinations and validation sets are shown in Table 2 . Results shown are averages based on 50 random iterations.

\section{DMI Prediction Accuracy Across Lactation Using Validation A}

Validation A exhibited comparable variation or similar sampling conditions for calibration and validation data sets; that is, all cows were included in calibration and validation sets. The milk FT-IR full spectral profile (511 wavenumbers) used alone as predictor traits in DMI prediction resulted in decreased prediction capacity with $\mathrm{R}_{\text {Val }}^{2}=0.30$ and $\mathrm{RMSEP}=2.91$ when validated using the external test set (Table 2). Milk yield explained $59 \%$ of the variation in DMI with RMSEP $=2.24$. Live weight added to MY improved DMI model performance, such that $\mathrm{R}_{\text {Val }}^{2}$ increased from 0.59 to 0.72 and RMSEP decreased from 2.24 to 1.83 . Addition of BCS did not improve model performance (results not shown).

In addition, the FT-IR spectra were added to the MY and LW data sets as predictor traits to test if the spectral profile might improve performance of the DMI prediction model. Results showed that $\mathrm{R}_{\text {Val }}^{2}$ increased from 0.72 to 0.81 and RMSEP decreased from 1.83 to 1.49. Furthermore, instead of using the full FT-IR milk spectral profile, FT-IR-predicted fat, protein, and lactose were added to the model individually as predictors along with MY and LW. When fat was added, $\mathrm{R}_{\text {Val }}^{2}$ increased from 0.72 to 0.78 and RMSEP decreased from 1.83 to 1.63 . The addition of protein showed a small improvement, with decreased RMSEP $=1.60$, and the FT-IR-predicted lactose showed no enhancement in the DMI prediction model.

\section{DMI Prediction Accuracy Across Lactation Using Validation $B$}

Prediction results observed for validation $\mathrm{B}$ indicated a lack of congruency with validation $A$ for $\mathrm{R}_{\text {Cal }}^{2}, \mathrm{R}_{\text {Val }}^{2}$, RMSEC, and RMSEP (Table 2). In addition, model performance in most cases was more robust in validation A than validation B. This can be explained as follows: in validation A, $20 \%$ of the records were randomly 


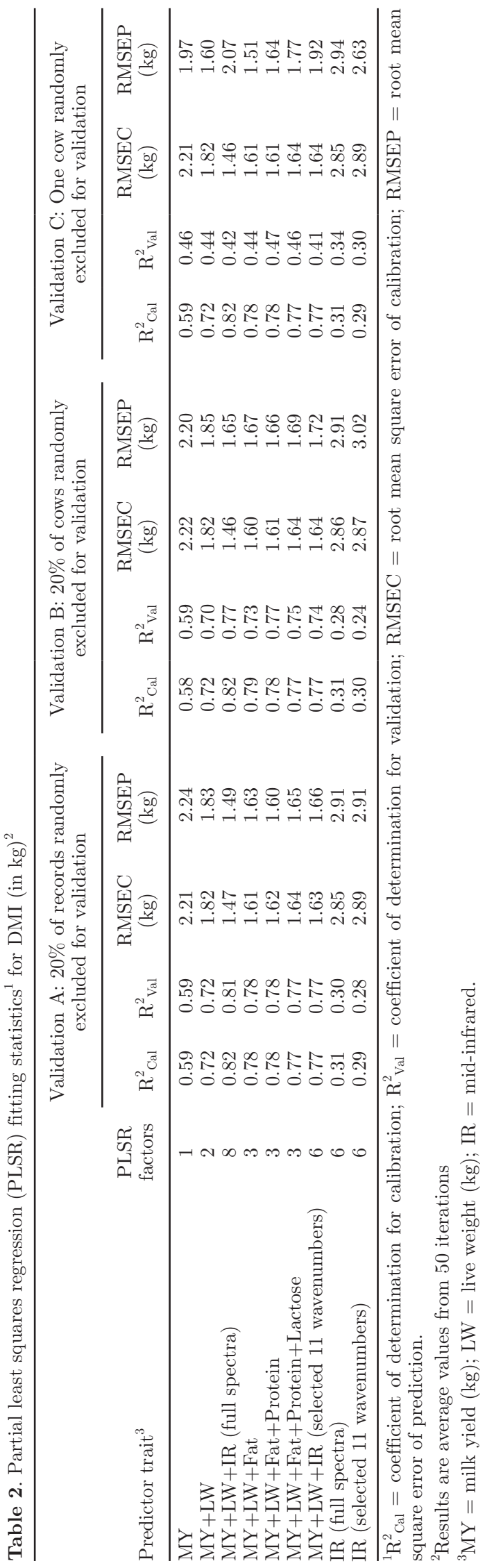

left out. As each cow has repeated observations, there is a close relationship between training and test data sets. However, in validation B, $20 \%$ of cows were randomly excluded for validation and therefore for some iterations, the training data set did not include all variation present in the test data set.

\section{DMI Prediction Accuracy Across Lactation Using Validation $C$}

Validation $\mathrm{C}$ results showed much lower $\mathrm{R}_{\text {Val }}^{2}$ compared with $\mathrm{R}_{\text {Cal }}^{2}$; this was due to the very small sample size with limited variation in the validation set. In validation $\mathrm{C}$, only records for one cow at a time were excluded for the validation. When individual model results from 50 iterations were observed, for some cases resulted $R_{\text {Val }}^{2}$ was either close to 0 or 1 . This is because there were 1 to 14 records per cow in a data set, and $\mathrm{R}_{\text {Val }}^{2}$ depended on the number of records in the validation data set of each specific cow.

\section{DMI Prediction Accuracy Within Lactation}

Dry matter intake predictions performed separately in different lactation stages indicated that mid- and late-lactation prediction results were comparable with across-lactation prediction accuracies (results not shown) when MY, LW, and FT-IR spectra were used as predictor traits. Relatively lower prediction accuracies were obtained when using only early-lactation data; this might be due to the limited number of cows compared with mid- and late-lactation stages. In the mid-lactation stage, MY explained notably larger DMI variation compared with early-, late-, and across-lactation periods.

\section{RFI Prediction Accuracy Using FT-IR Spectral Data Across and Within Lactation}

Residual feed intake prediction accuracies changed throughout lactation (Table 3). Overall RFI prediction models for the early lactation stage were better compared with across-lactation or mid and late lactation. During the early lactation stage, $\mathrm{R}^{2}=0.46(\mathrm{r}=0.68)$ and $\mathrm{RMSEP}=1.70$ with validation $\mathrm{A}$. Model accuracy decreased notably when $20 \%$ of the cows were randomly excluded for the validation B. However, this might be due to limited number of cows $(\mathrm{n}=31)$ : $\mathrm{R}^{2}$ was 0.29 $(\mathrm{r}=0.54)$, RMSEP was 2.00. However, in mid- and late-lactation stages, much lower prediction accuracies were detected $\left(\mathrm{R}^{2} \sim 0.1\right)$. In addition, the RFI prediction model was performed using FT-IR-predicted fat, protein, and lactose (results not shown). When fat was used as a predictor for RFI, it explained only $1 \%$ of 
(a)

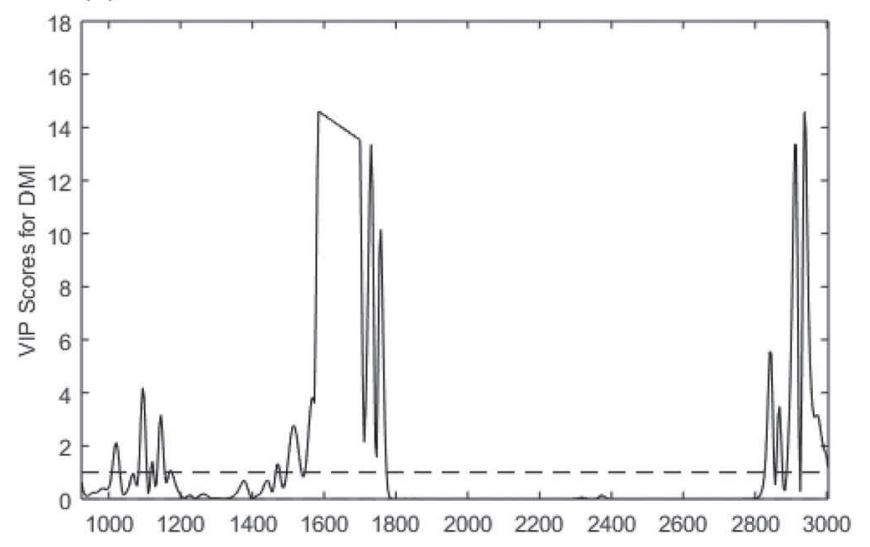

(b)

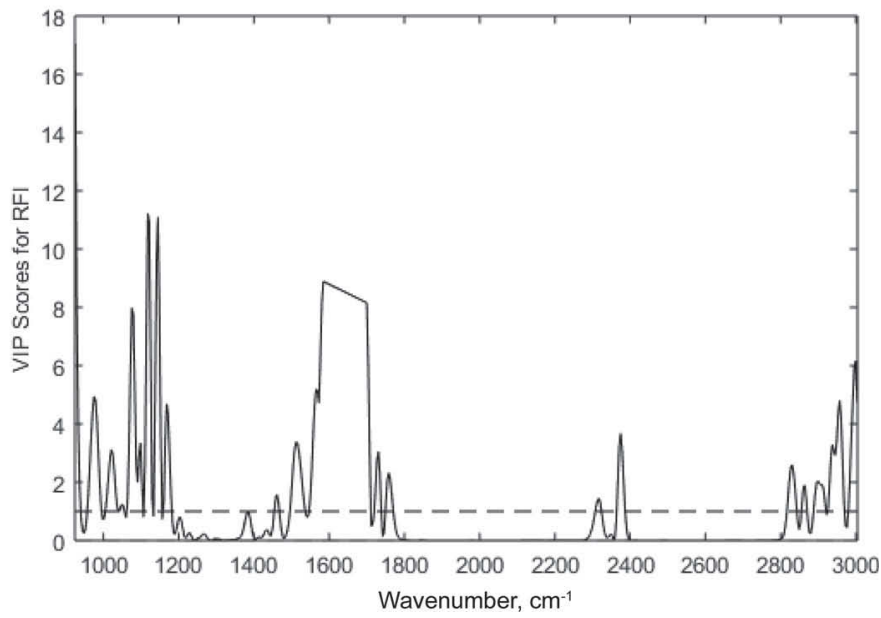

Figure 1. Variable importance in projection (VIP) scores of (a) DMI prediction model across lactation, and (b) residual feed intake (RFI) prediction model in early lactation plotted against wavenumber $\left(\mathrm{cm}^{-1}\right)$. the variation, with $\mathrm{RMSEP}=2.44$. Including protein improved the RFI model substantially $\left(\mathrm{R}^{2}=0.29\right.$ and RMSEP $=1.97)$. Adding lactose further improved the predictions $\left(\mathrm{R}^{2}=0.34\right.$ and $\left.\mathrm{RMSEP}=1.95\right)$.

\section{Selected FT-IR Wavenumbers for DMI Prediction Across Lactation}

Figure 1a illustrates variable importance in projection (VIP) scores and shows the most important spectral region in DMI prediction. The full FT-IR spectral profile explained $\sim 30 \%$ of the total variation, resulting in RMSEP $=2.91$. The $r$ PLS variable selection method identified the 11 most important wavenumbers for DMI prediction. Following selection of these 11 wavenumbers used to predict DMI, the subset of wavenumbers explained similar variation as the full FT-IR spectra (Table 2). Table 4 provides the 11 selected spectral wavenumbers, the corresponding chemical functional groups, the milk components, and feed and nutrient information. All selected wavenumbers corresponded to the major milk components fat, protein, and lactose regions of the FT-IR spectra.

\section{Selected FT-IR Wavenumbers for RFI at Early Lactation}

The VIP scores that showed the most important spectral regions in RFI prediction at the early lactation stage are presented in Figure 1b. The full FT-IR spectral profile explained $\sim 46 \%$ of the total variation, resulting in RMSEP $=1.70$ (Table 3 ). The $\mathrm{rPLS}$ variable selection method identified the 9 most important wavenumbers for RFI prediction. Following selection of these 9 wavenumbers used to predict RFI, the subset of wavenumbers explained similar variation as the full FT-IR spectra; $\mathrm{R}^{2}=0.43$ and RMSEP $=1.91$ when $20 \%$ of the randomly excluded records were used as the

Table 3. Partial least squares regression (PLSR) fitting statistics ${ }^{1}$ for residual feed intake using Fourier transform mid-infrared spectra at different lactation stages ${ }^{2}$

\begin{tabular}{|c|c|c|c|c|c|c|c|c|c|}
\hline \multirow[b]{2}{*}{ Lactation stage } & \multirow[b]{2}{*}{$\begin{array}{l}\text { PLSR } \\
\text { factors }\end{array}$} & \multicolumn{4}{|c|}{$\begin{array}{l}\text { Validation A: } 20 \% \text { of records } \\
\text { randomly excluded for validation }\end{array}$} & \multicolumn{4}{|c|}{$\begin{array}{l}\text { Validation B: } 20 \% \text { of cows } \\
\text { randomly excluded for validation }\end{array}$} \\
\hline & & $\mathrm{R}_{\mathrm{Cal}}^{2}$ & $\mathrm{R}_{\text {Val }}^{2}$ & $\begin{array}{l}\text { RMSEC } \\
(\mathrm{kg})\end{array}$ & $\begin{array}{l}\text { RMSEP } \\
(\mathrm{kg})\end{array}$ & $\mathrm{R}_{\mathrm{Cal}}^{2}$ & $\mathrm{R}_{\text {Val }}^{2}$ & $\begin{array}{l}\text { RMSEC } \\
(\mathrm{kg})\end{array}$ & $\begin{array}{l}\text { RMSEP } \\
(\mathrm{kg})\end{array}$ \\
\hline $\operatorname{Across}(1$ to $44 \mathrm{wk})$ & 8 & 0.27 & 0.24 & 1.42 & 1.46 & 0.28 & 0.20 & 1.41 & 1.50 \\
\hline Early (1 to $9 \mathrm{wk})$ & 6 & 0.57 & 0.46 & 1.58 & 1.70 & 0.60 & 0.29 & 1.53 & 2.00 \\
\hline Early (selected 9 wavenumbers) & 6 & 0.47 & 0.43 & 1.73 & 1.91 & 0.48 & 0.37 & 1.72 & 1.99 \\
\hline
\end{tabular}

$\overline{{ }^{1}} \mathrm{R}_{\text {Cal }}^{2}=$ coefficient of determination for calibration; $\mathrm{R}_{\text {Val }}^{2}=$ coefficient of determination for validation; RMSEC = root mean square error of calibration; RMSEP = root mean square error of prediction.

${ }^{2}$ Results are average values from 50 iterations. 
Table 4. Recursive weighted partial least squares regression selected important spectral wavenumbers for DMI prediction across lactation along with corresponding chemical functional groups, milk components, and feed and nutrient information

\begin{tabular}{|c|c|c|c|c|c|}
\hline Wavenumber $\left(\mathrm{cm}^{-1}\right)$ & $\begin{array}{l}\text { Milk } \\
\text { components }\end{array}$ & Nutrients & Feed & Bond & $\begin{array}{l}\text { Functional } \\
\text { group }\end{array}$ \\
\hline $3,003,2,949$ & Fat B & $\begin{array}{l}\text { Fatty acids, acetic, } \\
\text { butyric }\end{array}$ & Fermentable fiber & $\mathrm{C}-\mathrm{H}$ & Alkyl chain \\
\hline 1,796 & Fat A & $\begin{array}{l}\text { Fatty acids, acetic, } \\
\text { butyric }\end{array}$ & Fermentable fiber & $\mathrm{C}=\mathrm{O}$ & Carbonyl group \\
\hline 1,288 & $\begin{array}{l}\text { Protein } \\
\text { (amide III) }\end{array}$ & Amino acids & Crude protein & $\mathrm{C}-\mathrm{N}$ & Aromatic amines \\
\hline
\end{tabular}

validation set. However, when $20 \%$ of the cows were randomly excluded for the validation, RFI prediction accuracy was more robust when using the selected 9 wavenumbers compared with the full spectral data set. Table 5 provides the 9 selected spectral wavenumbers, the corresponding chemical functional groups, the milk components, and feed and nutrient information. All selected wavenumbers corresponded to major milk component regions, consistent with DMI predictions.

\section{Breed Differences}

The PLSR score plots of the FT-IR spectral profiles showed differences between the 2 breeds, Holstein and Jersey (Figure 2a). Discrimination was associated with the first PLSR component (latent variable 1, LV1), mainly due to the fat region (2 major peaks), when evaluated using the corresponding loadings plot (Figure $2 \mathrm{~b}$ ). When only Holstein data were used to perform DMI predictions, the prediction results $\left(\mathrm{R}_{\text {Val }}^{2}\right.$ and $\mathrm{RM}-$ SEP) were close to that obtained from the combined model. However, when only Jersey data were used, prediction accuracy was notably reduced compared with the combined breed data (Table 6). This can be explained by the smaller Jersey sample size and record number compared with Holsteins. Biased predictions were observed when DMI models were calibrated on one breed and validated on the other breed (Table 6). This is because the 2 breeds differ notably in DMI and milk composition; therefore, the calibration set does not cover the variation of validation set. The rPLS selected FT-IR regions for within breed were similar to the across-breed regions.

\section{DISCUSSION}

\section{Assessment of Proper Validation for Model Robustness}

The objective of validation was to ensure that the model was robust in predicting new data sets of similar types and to find optimal dimensionality in the PLSR model to avoid over- or under-fitting. As stated by Esbensen and Geladi (2010), "Validation cannot be understood by focusing on methods of validation only; validation must be based on knowledge of the underlying definitions, objectives, methods, effects and consequences." Therefore, proper validation will guarantee that a particular prediction model will function based on its objective.

It is also important to consider how the model will be validated when designing and selecting a training data set for modeling (Esbensen and Geladi, 2010). Possible future variation in the data set must be included in training the model, and the resulting validation data set must include potential future variation to obtain a robust prediction model. In the present study, data were collected on only one stable farm (indoor-fed cows) in a specific period of the year (April to August), and therefore had limited data variation. Thus, prediction models obtained in this study are specific to these data circumstances. Expansion in variability

Table 5. Recursive weighted partial least squares regression selected important spectral wavenumbers for residual feed intake prediction in early lactation along with corresponding chemical functional groups, milk components, and feed and nutrient information

\begin{tabular}{|c|c|c|c|c|c|}
\hline Wavenumber $\left(\mathrm{cm}^{-1}\right)$ & Milk components & Nutrients & Feed & Bond & Functional group \\
\hline 1,789 & Fat A & $\begin{array}{l}\text { Fatty acids, acetic, } \\
\text { butyric }\end{array}$ & Fermentable fiber & $\mathrm{C}=\mathrm{O}$ & Carbonyl group \\
\hline 1,249 & Protein (amide III) & Amino acids & Crude protein & $\mathrm{C}-\mathrm{N}$ & Aromatic amines \\
\hline $1,079,987,968,948,944$ & Lactose & Propionic (glucose) & Sugar, starch & $\mathrm{O}-\mathrm{H}$ & Hydroxyl group \\
\hline
\end{tabular}


(a)

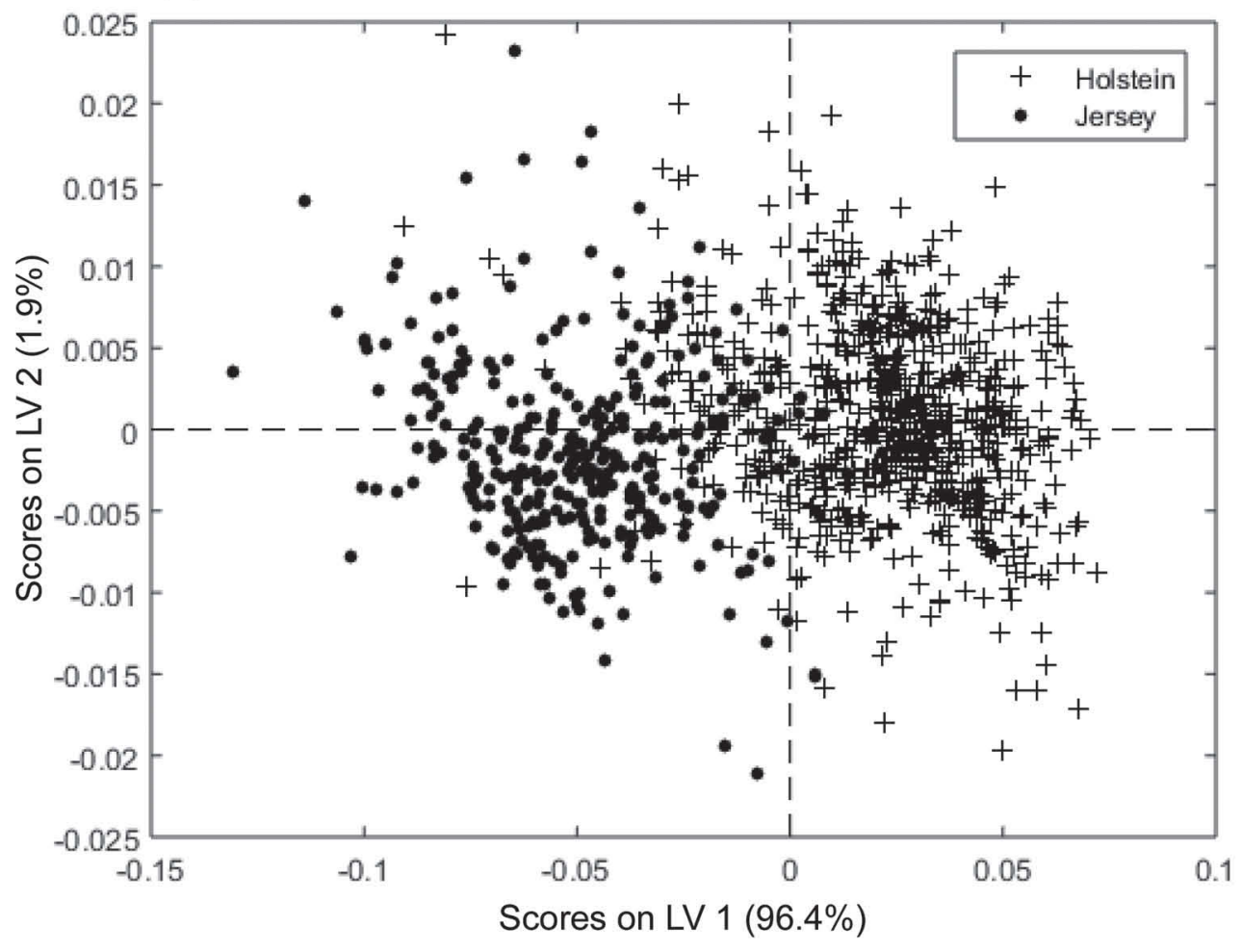

(b)

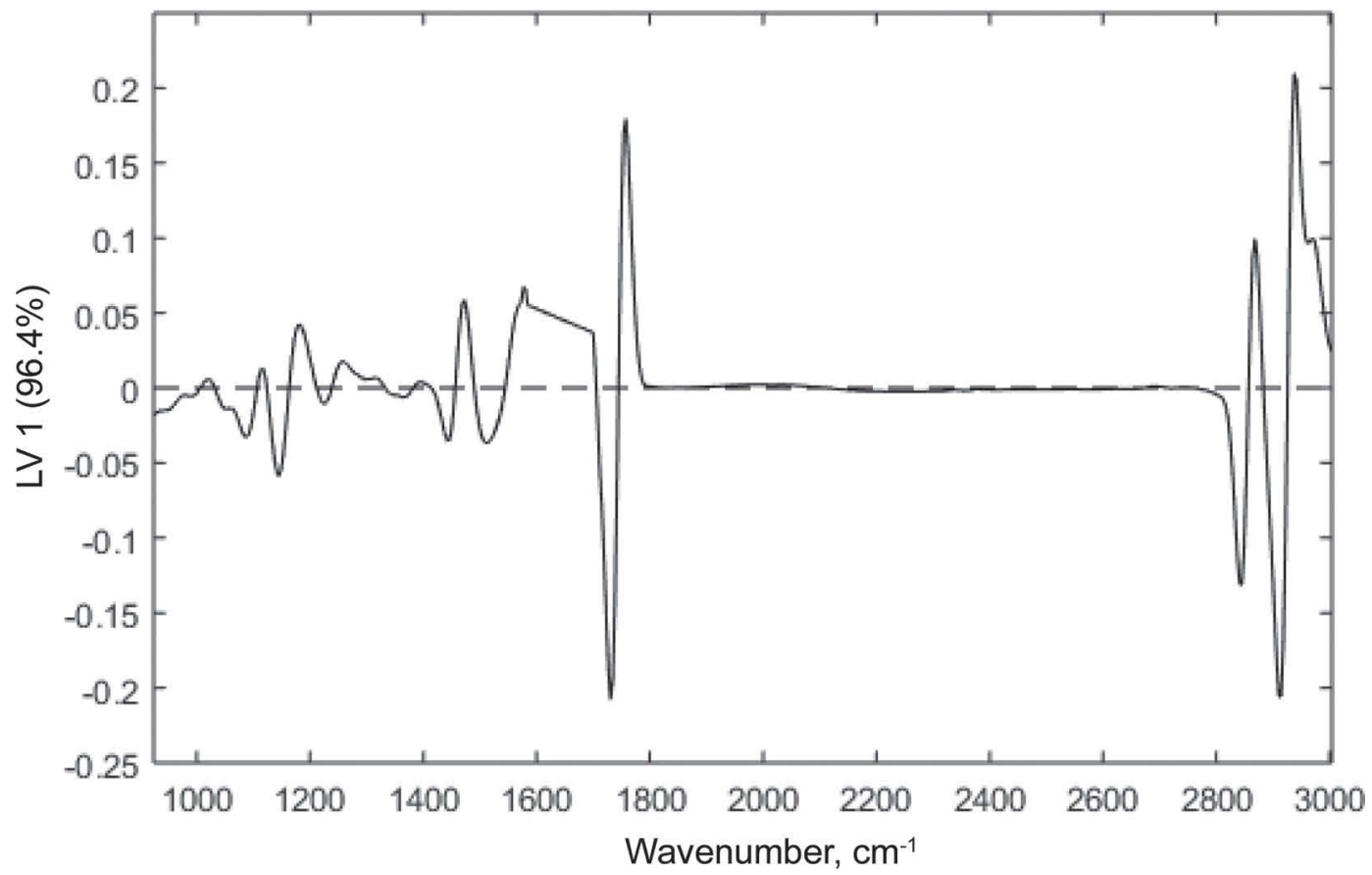

Figure 2. Score plot of first 2 latent variables (LV1 and LV2) of partial least squares regression model showing (a) discrimination between 2 breeds, Holstein and Jersey, and (b) loading plot of first latent variable LV1 plotted against wavenumber $\left(\mathrm{cm}^{-1}\right)$. 


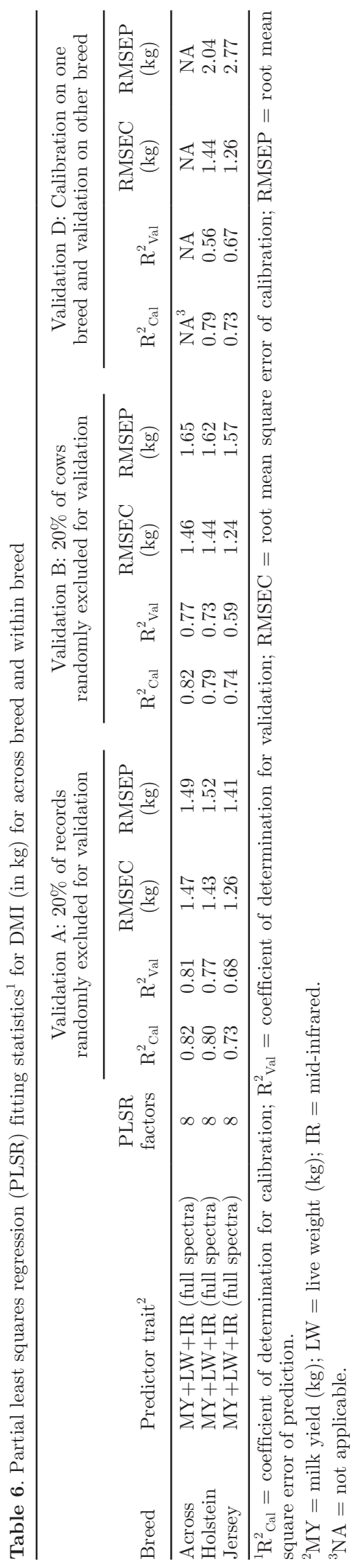

within the data set is required to ensure higher robustness of the developed prediction models. In the present study, both breeds were combined to increase variation in data. The objective of validation in the present study does not only refer to the current modeling scenario. Cross-validation was used to assess the optimal dimensionality of the PLSR model. Test set validation was used to evaluate the obtained prediction models. The DMI models were evaluated using 3 types of external test sets, validation $\mathrm{A}, \mathrm{B}$, and $\mathrm{C}$, with 50 iterations as previously described.

In validation A, because $20 \%$ of records were randomly excluded, records of the same cow were present in the training and validation sets. Therefore, in validation $\mathrm{A}$, the test data set included all possible variation in the training set; that is, variation in the 140 cows, including breeds or any other sampling conditions. For this reason, validation A probably gives prediction results that are too optimistic. However, in validation B, a realistic future circumstance was considered; instead of considering $20 \%$ of the records randomly as the validation set, $20 \%$ of the cows were randomly excluded for validation. This served to elucidate how the model would perform when it was used to predict DMI independent of new cow records. This explains why a higher prediction error (RMSEP) was observed in validation B than in validation A (Table 2). When $20 \%$ of cows were entirely excluded for validation for 50 different iterations, in some cases the training set did not include all possible variation of the test set. Therefore, the training set must contain potential future variation to obtain robust prediction models. For this study, validation B was more suitable, as all generated prediction models were validated with respect to realistic future scenarios. In this way, the training and test data sets were representations of future circumstances.

In validation $C$, much lower $R_{\text {Val }}^{2}$ was observed compared with $R_{\text {Cal }}^{2}$ (Table 2), indicating that the $R^{2}$ value was sensitive to the range of data used in the model. Typically, a larger range resulted in higher $\mathrm{R}^{2}$ values, as we observed in validations $\mathrm{A}$ and $\mathrm{B}$. Therefore, judging only by $\mathrm{R}^{2}$ is not a viable criterion and the standard error of prediction (RMSEP) is the best choice when evaluating model performance. Davies and Fearn (2006) reported that RMSEP is a measure of variability of the difference between predicted and reference values for a validation sample data set; therefore, RMSEP should not be sensitive if the model is robust. In most cases validation $\mathrm{C}$ exhibited a lower or similar RMSEP compared with validation $\mathrm{A}$ and $\mathrm{B}$. The model prediction capacity differs from model fitness capability; that is, the capacity of the generated model to estimate new or future samples, which are not used to train the model. 


\section{Biological Interpretation of the Selected Important FT-IR Wavenumbers}

The milk fat FT-IR profile information is based primarily on 2 specific regions. The spectral region between $\sim 1,700$ and $1,800 \mathrm{~cm}^{-1}$ exhibits strong absorbance bands due to the carbonyl $(\mathrm{C}=\mathrm{O})$ group of milk lipids and is commonly referred to as fat $\mathrm{A}$. The second fat region is located between $\sim 2,800$ and $3,000 \mathrm{~cm}^{-1}$ due to a $\mathrm{C}-\mathrm{H}$ group and is commonly referred to as fat B (Andersen et al., 2002; Iñón et al., 2004). In the present study, the selected wavenumbers $3,003 \mathrm{~cm}^{-1}$ and $2,949 \mathrm{~cm}^{-1}$ for DMI, and $3,003 \mathrm{~cm}^{-1}$ and 2,976 $\mathrm{cm}^{-1}$ for RFI might be due to milk fat B and selected wavenumbers $1,796 \mathrm{~cm}^{-1}$ for DMI and $1,789 \mathrm{~cm}^{-1}$ for RFI might be assigned to milk fat A. Selected wavenumbers $1,288 \mathrm{~cm}^{-1}$ for DMI and $1,249 \mathrm{~cm}^{-1}$ for RFI might be due to milk protein. Milk protein amide III has an FT-IR peak that occurs near $1,300 \mathrm{~cm}^{-1}$, mainly due to C-N stretching (Dufour, 2009; Lei et al., 2010). The remaining 8 selected wavenumbers between 925 and $1,103 \mathrm{~cm}^{-1}$ for DMI and 5 selected wavenumbers between 944 and $1,079 \mathrm{~cm}^{-1}$ might be assigned to milk lactose. The FT-IR spectral region near the 930-1,190 $\mathrm{cm}^{-1}$ region corresponds to lactose, due to the presence of a hydroxyl (O-H) group (Andersen et al., 2002; Lei et al., 2010).

Belanche et al. (2014) developed the PLSR model to quantify feed DM in the rumen, and results showed specifically that the infrared absorption region was between 976 and $1,086 \mathrm{~cm}^{-1}$. This region corresponded to infrared absorbance by sugars, starch, cellulose, lignin, cutin, suberin, fatty acids, and aldehydes. In the present study, this infrared region was selected as one of the important regions in the milk spectral profile, perhaps due to a prominent lactose milk component. Therefore, the most important FT-IR spectral regions in DMI and RFI prediction were fat $\mathrm{A}$, fat $\mathrm{B}$, milk protein amide III, and lactose peaks.

The DMI prediction results were similar when the model was developed using predictors MY, LW, FTIR-predicted fat, protein, and lactose compared with the model developed using predictor traits MY, LW, and selected FT-IR regions for validation methods A and B (Table 2). Adding fat improved the DMI model to some extent; however, adding protein showed little improvement. Selected FT-IR regions indicated that lactose peaks in milk spectral data were one of the important regions for DMI, and lactose addition did not show further model improvement. This might also be due to correlations between milk contents. In the present study, positive and negative correlations were detected for fat-protein $(\mathrm{r}=0.84)$, fat-lactose $(\mathrm{r}=$ $-0.40)$, and protein-lactose $(\mathrm{r}=-0.37)$. However, VIP score plots (Figure $2 \mathrm{~b}$ ) showed a similar pattern, where major peaks were exhibited in the fat and protein regions for the milk spectra and relatively minor peaks were in the lactose region. Thus, major variation in milk spectra for DMI prediction across lactation was largely due to the milk fat regions, followed by protein regions.

In the case of RFI prediction, selected important FTIR wavenumbers corresponded to fat, protein, and lactose contents, although RFI values were corrected for these major milk components (using ECM). When the RFI prediction model was performed using FT-IR-predicted fat, protein, and lactose, the major variation in milk spectra for RFI prediction at early lactation was primarily due to the milk protein, followed by lactose regions.

Hoover and Miller (1991) reported that fat in feed converts to nutrient fatty acids in the rumen, which becomes milk fat; $\mathrm{CP}$ is converted to nutrient AA and subsequently milk protein; sugar and starch in feed is converted to propionic acid (glucose) and then milk lactose. This might explain why the fat, protein, and lactose regions of the milk infrared spectral profile were most informative.

When we look at the VIP score plot for RFI (Figure $2 \mathrm{~b}$ ), an additional peak can be seen in the infrared region near 2,200 to $2,400 \mathrm{~cm}^{-1}$. This region may not be predictive for RFI because the region does not provide any known relevant chemical information regarding milk samples. This might be due to atmospheric $\mathrm{CO}_{2}$ in the laboratory environment (Andersen et al., 2002; Iñón et al., 2004). So the correlation here does not imply causation. The rPLS variable selection procedure also did not select this spectral region as predictive for RFI.

\section{Usefulness in Practice}

McParland et al. (2014) found a correlation of $\sim 0.70$ $\left(\mathrm{R}^{2}=0.49\right)$ between actual and predicted energy intake in lactating Holstein Friesian dairy cows when evaluated using external validation. In that study, FT-IR spectra of morning and evening milk samples along with milk yield were used as predictor traits. Huntington et al. (2011) reported similar accuracy in predicting daily DMI from near-infrared reflectance (NIR) spectroscopy of fecal sample analysis in growing Angus bulls. We detected higher correlations, $\mathrm{r}=0.90$ and $\mathrm{r}=$ 0.88 , when evaluating using external test sets (validation $\mathrm{A}$ and $\mathrm{B}$ ), where weekly daily DMI averages were predicted using MY, LW, and FT-IR spectral profiles., Similar to results of the present study, McParland et al. (2014) found a correlation of 0.65 between actual and predicted RFI in early lactation, when RFI was 
predicted using the FT-IR spectral profile. However, notably lower correlations were detected for mid, late, and across lactation compared with McParland et al. (2014).

The primary factors influencing cow feed intake include MY, stage of lactation, and BW. Other factors include forage quality and availability, amount and type of supplements, environment, and overall cow health. A mature cow will generally consume 1 to $3 \%$ of its BW. Consumption of low-quality feeds might equal 1 to $2 \%$ of $\mathrm{BW}$, whereas green pasture might be 2 to $3 \%$ (Wieland, 2002). However, models developed in this study were specific to cows fed a TMR indoors. When populations with different production environments are available; for example, grass-fed cows, the FT-IR profile might add additional information to improve the DMI and RFI prediction models, perhaps due to differences in some of the milk fatty acid profiles.

For practical applications, it is likely that milk spectral data from test-day records will be used instead of weekly averages. Such a data set will be noisy due to different factors having an influence on a particular test day, indicating there is high chance of obtaining less accurate predictions.

\section{Added Value of FT-IR Milk Spectral Profile}

Predictor traits currently available for RFI as efficiency or feed intake predictions include MY, milk composition, and, for many cows, LW. Therefore, the question of interest is whether FT-IR milk spectra can add additional information that is not currently available. The DMI prediction models using different trait combinations (Table 2) indicated that reasonably good predictions were possible with combined predictor traits; that is, MY, LW and full FT-IR spectra. However, major contributions in the milk spectral profile for DMI and RFI predictions were due to the milk components fat, protein, and lactose. Comparable prediction results were obtained when using FT-IR-predicted fat, protein, and lactose instead of full spectra. These results indicated that the FT-IR milk spectral profile did not add new information. Therefore, in practice, if full FT-IR spectral data are not stored, it is possible to achieve similar DMI or RFI prediction results based on standard milk control data.

\section{CONCLUSIONS}

We summarized the utility of FT-IR spectral data to predict DMI and RFI. Model validation using different independent test data sets with several iterations showed better prediction accuracies when random records were excluded for validation compared with exclusion of random cows for validation. Comparable prediction results were obtained when FT-IR-predicted fat, protein, and lactose instead of full spectra for prediction, indicating that FT-IR spectral data does not add significant new information to improve DMI and RFI prediction models. For DMI, the major variation in milk spectra was due to the milk fat region, whereas for RFI, the major variation in milk spectra was due to the milk protein region. Models developed in this study were specific to indoor-fed cows.

\section{ACKNOWLEDGMENTS}

This study was financially supported by two projects: "FT-IR spektre i mælk: Genetisk variation og effekt på sundhed, frugtbarhed og energibalance" of the Milk Levy Fund, Denmark (2015-2017), and Robust and Efficient Dairy Cows-REFFICO, project number: 34009-14-0848 of Grønt Udviklings-og Demonstrations Program (GUDP) (2015-2018).

\section{REFERENCES}

Andersen, S. K., P. W. Hansen, and H. V. Andersen. 2002. Vibrational Spectroscopy in the Analysis of Dairy Products and Wine. Pages 3672-3682 in Handbook of Vibrational Spectroscopy. Vol. 5. J. M. Chalmers and P. R. Griffiths, ed. Wiley, Chichester, UK.

Basarab, J. A., K. A. Beauchemin, V. S. Baron, K. H. Ominski, L. L. Guan, S. P. Miller, and J. J. Crowley. 2013. Reducing GHG emissions through genetic improvement for feed efficiency: Effects on economically important traits and enteric methane production. Animal 7:303-315.

Belanche, A., M. R. Weisbjerg, G. G. Allison, C. J. Newbold, and J. M. Moorby. 2014. Measurement of rumen dry matter and neutral detergent fiber degradability of feeds by Fourier-transform infrared spectroscopy. J. Dairy Sci. 97:2361-2375. https://doi.org/10.3168/ jds.2013-7491.

Berry, D. P., and J. J. Crowley. 2013. Cell biology symposium: Genetics of feed efficiency in dairy and beef cattle. J. Anim. Sci. 91:1594-1613. https://doi.org/10.2527/jas.2012-5862.

Bonfatti, V., G. Di Martino, and P. Carnier. 2011. Effectiveness of mid-infrared spectroscopy for the prediction of detailed protein composition and contents of protein genetic variants of individual milk of Simmental cows. J. Dairy Sci. 94:5776-5785. https://doi. org/10.3168/jds.2011-4401.

Connor, E. E., J. L. Hutchison, K. M. Olson, and H. D. Norman. 2012. Triennial Lactation Symposium: Opportunities for improving milk production efficiency in dairy cattle. J. Anim. Sci. 90:1687-1694.

Dado, R. G., and M. S. Allen. 1994. Variation in and relationships among feeding, chewing and drinking variables for lactating dairy cows. J. Dairy Sci. 77:132-144.

Davies, A., and T. Fearn. 2006. Back to basics: Calibration statistics. Spectrosc. Eur. 18:31-32.

De Marchi, M., V. Toffanin, M. Cassandro, and M. Penasa. 2014. Invited review: Mid-infrared spectroscopy as phenotyping tool for milk traits. J. Dairy Sci. 97:1171-1186. https://doi.org/10.3168/ jds.2013-6799.

Dehareng, F., C. Delfosse, E. Froidmont, H. Soyeurt, C. Martin, N. Gengler, A. Vanlierde, and P. Dardenne. 2012. Potential use of milk mid-infrared spectra to predict individual methane emission of dairy cows. Animal 6:1694-1701. https://doi.org/10.1017/ S1751731112000456. 
Dufour, E. 2009. Principles of infrared spectroscopy. Pages 3-27 in Infrared Spectroscopy for Food Quality Analysis and Control. 1st ed. D.-W. Sun, ed. Academic Press, London, UK.

Esbensen, K. H. 2000. Multivariate Data Analysis-In Practice, 4th ed. CAMO, Oslo, Norway.

Esbensen, K. H., and P. Geladi. 2010. Principles of proper validation: Use and abuse of re-sampling for validation. J. Chemometr. 24:168-187. https://doi.org/10.1002/cem.1310.

Hoover, W. H., and T. K. Miller. 1991. Rumen digestive physiology and microbial ecology. Pages 311-325 in The Veterinary Clinics of North America: Food Animal Practice. C. J. Sniffen and T. H. Herdt, ed. Vol. 7, No 2. W. B. Saunders Co., Philadelphia, PA.

Huntington, G. B., E. S. Leonard, and J. C. Burns. 2011. Technical note: Use of near-infrared reflectance spectroscopy to predict intake and digestibility in bulls and steers. J. Anim. Sci. 89:11631166. https://doi.org/10.2527/jas.2010-3376.

Hutjens, M. F. 2005. Revisiting feed efficiency and its economic impact. Pages 177-182 in Proc. Four-State Dairy Nutr. Mgmt. Conf. Midwest Plan Service, Iowa State University, Ames.

Iñón, F. A., S. Garrigues, and M. De La Guardia. 2004. Nutritional parameters of commercially available milk samples by FTIR and chemometric techniques. Anal. Chim. Acta 513:401-412. https:// doi.org/10.1016/j.aca.2004.03.014.

Kristensen, T. 1986. Method for estimation of body condition of dairy cows. Report 615. National Institute of Animal Science, Tjele, Denmark.

Lei, Y., Q. Zhou, Y. L. Zhang, J. B. Chen, S. Q. Sun, and I. Noda. 2010. Analysis of crystallized lactose in milk powder by Fouriertransform infrared spectroscopy combined with two-dimensional correlation infrared spectroscopy. J. Mol. Struct. 974:88-93. https://doi.org/10.1016/j.molstruc.2009.12.030.

Løvendahl, P., C. Ridder, and N. C. Friggens. 2010. Limits to prediction of energy balance from milk composition measures at individual cow level. J. Dairy Sci. 93:1998-2006.

Lowman, B. G., N. Scott, and S. Somerville. 1976. Condition scoring of cattle. Tech. Bull. 6:1-29. East of Scotland College of Agriculture, Edinburgh, UK.

Martens, H., and T. Naes. 1989. Multivariate Calibration. John Wiley \& Sons Ltd., Chichester, UK.

McParland, S., G. Banos, B. McCarthy, E. Lewis, M. P. Coffey, B. O'Neill, M. O'Donovan, E. Wall, and D. P. Berry. 2012. Validation of mid-infrared spectrometry in milk for predicting body energy status in Holstein-Friesian cows. J. Dairy Sci. 95:7225-7235. https://doi.org/10.3168/jds.2012-5406.

McParland, S., G. Banos, E. Wall, M. P. Coffey, H. Soyeurt, R. F. Veerkamp, and D. P. Berry. 2011. The use of mid-infrared spectrometry to predict body energy status of Holstein cows. J. Dairy Sci. https://doi.org/10.3168/jds.2010-3965.

McParland, S., E. Lewis, E. Kennedy, S. G. Moore, B. McCarthy, M. O'Donovan, S. T. Butler, J. E. Pryce, and D. P. Berry. 2014. Mid-infrared spectrometry of milk as a predictor of energy intake and efficiency in lactating dairy cows. J. Dairy Sci. 97:5863-5871. https://doi.org/10.3168/jds.2014-8214.

Rinnan, A., M. Andersson, C. Ridder, and S. B. Engelsen. 2014. Recursive weighted partial least squares (rPLS): An efficient variable selection method using PLS. J. Chemometr. 28:439-447. https:// doi.org/10.1002/cem.2582.

Rinnan, A., L. Nørgaard, and F. Van Den Berg. 2009. Data Pre-processing. Pages 29-50 in Infrared Spectroscopy for Food Quality Analysis and Control. 1st ed. D.-W. Sun, ed. Academic Press, London, UK. https://doi.org/10.1016/B978-0-12-374136-3.00002-X.

Rutten, M. J., H. Bovenhuis, K. A. Hettinga, H. J. van Valenberg, and J. A. van Arendonk. 2009. Predicting bovine milk fat composition using infrared spectroscopy based on milk samples collected in winter and summer. J. Dairy Sci. 92:6202-6209. https://doi. org/10.3168/jds.2009-2456.

Rutten, M. J. M., H. Bovenhuis, J. M. Heck, and J. A. van Arendonk. 2011. Prediction of $\beta$-lactoglobulin genotypes based on milk Fourier transform infrared spectra. J. Dairy Sci. 94:4183-4188. https:// doi.org/10.3168/jds.2011-4149.

Savitzky, A. and M. J. E. Golay. 1964. Smoothing and differentiation of data by simplified least squares procedures. Anal. Chem. 36:1627-1638.

Sjaunja, L. O., L. Baevre, L. Junkkarinen, J. Pedersen, and J. Setala. 1990. A Nordic proposal for an energy corrected milk (ECM) formula. (Performance recording of animals: state of the art 1990). Pages 156-157 in Proc. European Federation of Animal Science (EAAP) Publication 50, Centre for Agricultural Publishing and Documentation, Wageningen, the Netherlands.

Soyeurt, H., F. Dehareng, N. Gengler, S. McParland, E. Wall, D. P. Berry, M. Coffey, and P. Dardenne. 2011. Mid-infrared prediction of bovine milk fatty acids across multiple breeds, production systems, and countries. J. Dairy Sci. 94:1657-1667. https://doi. org/10.3168/jds.2010-3408.

Vallimont, J. E., C. D. Dechow, J. M. Daubert, M. W. Dekleva, J. W. Blum, C. M. Barlieb, W. Liu, G. A. Varga, A. J. Heinrichs, and C. R. Baumrucker. 2011. Short communication: Heritability of gross feed efficiency and associations with yield, intake, residual intake, body weight, and body condition score in 11 commercial Pennsylvania tie stalls. J. Dairy Sci. 94:2108-2113. https://doi. org/10.3168/jds.2010-3888.

Waldo, D. R., and N. A. Jorgensen. 1981. Forages for high animal production: Nutritional factors and effects of conservation. J. Dairy Sci. 64:1207-1229.

Wieland, D. 2002. Understanding dry matter intake. BEEF Magazine. http://beefmagazine.com $/ \mathrm{mag} /$ beef_understanding_dry_ matter?page $=1$.

Wold, S., H. Martens, and H. Wold. 1983. The multivariate calibration problem in chemistry solved by the PLS method. Pages 286-293 in Proc. Conf. on Matrix Pencils, Lectures Notes in Mathematics. A. Ruhe and B. Kagstrom, ed. Springer, Heidelberg, Germany. 